\title{
Automated and interactive evaluation of welding producibility in an multidisciplinary design optimization environment for aircraft components
}

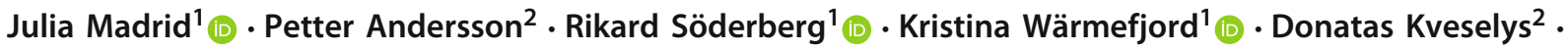 \\ Lars Lindkvist ${ }^{1}$ (I) $\cdot$ Johan Lööf ${ }^{2}$
}

Received: 21 September 2020 / Accepted: 17 September 2021 / Published online: 22 October 2021

(c) The Author(s) 2021

\begin{abstract}
The automation capabilities and virtual tools within engineering disciplines, such as structural mechanics and aerodynamics, enable efficient Multidisciplinary Design Optimization (MDO) approaches to evaluate and optimize the performance of a large number of design variants during early design stages of aircraft components. However, for components that are designed to be welded, in which multiple functional requirements are satisfied by one single welded structure, the automation and simulation capabilities to evaluate welding-producibility and predict welding quality (geometrical deformation, weld bead geometrical quality, cracks, pores, etc) are limited. Besides the complexity of simulating all phenomena within the welding process, one of the main problems in welded integrated components is the existing coupling between welding quality metrics and product geometry. Welding quality can vary for every new product geometrical variant. Thus, there is a need of analyzing rapidly and virtually the interaction and sensitivity coefficients between design parameters and welding quality to predict welding producibility. This paper presents as a result an automated and interactive welding-producibility evaluation approach. This approach incorporates a data-based of welding-producibility criteria, as well as welding simulation and metamodel methods, which enable an interactive and automated evaluation of welding quality of a large number of product variants. The approach has been tested in an industrial use-case involving a multidisciplinary design process of aircraft components. The results from analyzing the welding-producibility of a set of design variants have been plotted together with the analysis results from other engineering disciplines resulting in an interactive tool built with parallel coordinate graphs. The approach proposed allows the generation and reuse of welding producibility information to perform analyses within a big spectrum of the design space in a rapid and interactive fashion, thus supporting designers on dealing with changes and taking fact-based decisions during the multidisciplinary design process.
\end{abstract}

Keywords Welding producibility $\cdot$ Design for welding $\cdot$ Welding simulation $\cdot$ Metamodel $\cdot$ Automated multidisciplinary design optimization $\cdot$ Aerospace

\section{Introduction}

Multidisciplinary Design Optimization (MDO) approaches in the aerospace industry involve trade-offs between various engineering disciplines for the objective of reducing mass, fuel consumption, manufacturing costs and emissions while increasing product performance [1]. The automation of the

Julia Madrid

julia.madrid@chalmers.se

1 Department of Industrial and Materials Science, Chalmers University of Technology, Gothenburg, Sweden

2 GKN Aerospace Engine Systems, Trollhättan, Sweden analysis and optimization activities within the MDO process of aerospace products is constantly under development [13]. Over the last few years, MDO approaches have benefitted from the maturation of computer-aided modeling, automation and statistical techniques, which have made possible the efficient evaluation and optimization of the performance of a large number of design variants $[2,4-7]$. One of the objectives has been to account for the many design changes that occur in early design phases.

However, for welded and integrated products, in which multiple functions are satisfied by a single continuous structure, the automation and simulation capabilities to evaluate welding producibility and predict welding quality 
are limited as discussed in Madrid et al. [8]. The consequence is that predictions of welding producibility are often neglected in early design analyses. Instead, the evaluation of welding producibility relies on expert judgement and physical testing. If the objective is to analyze a large number of geometrical design variants, this approach can become costly. The sequential approach "product performance first and producibility seconD" can lead to designs that are performance-optimized but may cause producibility problems and, consequently, large manufacturing quality variation rates and defects during production.

In welded aerospace applications, manufacturing quality variation and defects can cause design modifications, due to the highly integrated nature of the components (geometrical design is coupled to the quality achieved during welding). Design modifications can cause increments in lead time and detriments in product performance, thereby decreasing customer satisfaction.

The scope of this paper is to present an approach that enables producibility evaluations in an automated industrial MDO environment for highly functional integrated products that need to be welded, such as aircraft components. The proposed approach includes interactive support of designers from the welding producibility standpoint during multidisciplinary design space exploration and analysis activities, such as design variants generation, evaluation and optimization.

Section 2 of this paper presents a review of the state-of-theart in Multidisciplinary Design Automation with a focus on methods and tools that consider welding evaluations. Section 3 proposes and explains the approach to automatically and interactively evaluate welding producibility by predicting the welding quality of a number of design variants within an MDO environment. Thereafter, the approach is evaluated in an industrial case study, which is presented in Sect. 4. Section 5 covers the discussion of the approach and the case study. Section 6 covers conclusions.

The research work published in this paper builds upon a seven-year academic-industrial collaboration aimed at developing methods and tools with which to predict product quality after welding, in addition to controlling welding - manufacturing variation and defects during early design phases. In this paper, the results from a number of previous research publications have been incorporated, see [8-11].

\section{State-of-the-art}

\subsection{Automated and interactive Multidisciplinary Design Optimization (MDO)}

Automated MDO approaches begin by parameterizing component geometry and setting a design space defined by a number of design parameters [12]. Each design parameter defines a single dimension of the design space, in which each point represents a potential design variant. Strategies to explore the design space can be summarized in three steps according to Kang et al. [13]: define the design space, populate it with design variants and analyze them to evaluate performance quality in order to decide on which design variants to further develop. Multidisciplinary optimization techniques involving different methods and simulation tools are then employed to perform multidisciplinary analysis upon the population of design variants.

Important advancements in automated Multidisciplinary Design Optimization have occurred in the field of mechanical engineering and aerodynamics to optimize product geometry $[2,4-6]$. For example, the automation capabilities within Computer-Aided Design (CAD) software have enabled design engineers to automatically generate a large number of different design variants through the creation of master CAD models $[1,14]$. At the same time, there are significant achievements to evaluate these models by means of automated analysis (AnsysWorkbench ${ }^{\mathrm{TM}}$, Hyperworks ${ }^{\mathrm{TM}}$, Siemens Advanced Simulation ${ }^{\mathrm{TM}}$ ).

Furthermore, the incorporation of statistical analysis and Design of Experiments (DoE) techniques for design space exploration has enabled building metamodels to predict product performance [5,15-17]. Metamodels are prediction models based on simulations that allow the estimation of the functional performance of parametric combinations (design variants) within the design space that have not been simulated [5,16].

As a result, automated MDO approaches speed up the design generation and analysis processes at the same time as they create knowledge about product behavior in relation to design parameters. The benefits are that many variants are explored and kept until enough knowledge is gained, which allows designers to be flexible and react rapidly to requirements changes from the Original Equipment Manufactures (OEMs).

\subsection{Manufacturing evaluations in automated MDO}

In literature, research studies can be found that cover the automation of producibility evaluations with the attempt of integrating manufacturing as an additional discipline in Multidisciplinary Design. Examples include the creation of expert systems that incorporate established Design for Manufacturing and producibility guidelines using Knowledge Based Engineering to achieve design automation [18,19]. As a result, information models have been developed together with CAD-based system tools aimed at manufacturing cost optimization [20-22].

Numerous examples can be found for machining process evaluations based on parametric models and interactive CAD/CAM (Computer Aided Manufacturing) environments 
[21-25]. For example, Hoefer et al. [25] presented a software platform for conducting automated manufacturability analyses during conceptual design. In their study, machinability is defined by a score or index based on accessibility characteristics. Khodaygan [21] incorporates in the machinability evaluation known machining process capability data and sensitivity coefficients of design parameters. Söderberg [22] proposed a system of tolerance analysis, which integrates CAD models with manufacturing data in order to calculate the minimum manufacturing cost for every resulting tolerance. Latest research has been focusing on assessing the manufacturability of Additive Manufacturing methods [26].

Concerning welding processes, there have been attempts to create tools for automated and interactive evaluations of CAD geometries to estimate welding process costs $[20,27$, 28] Stolt et al. [29] presented a case study to facilitate welding manufacturing knowledge into a multidisciplinary design environment by automating the processes of formatting and managing welding knowledge in a platform. In their study, they also provided a manufacturability index based on knowledge extracted from welding experts.

However, a common problem among all these tools and approaches designed to perform automated producibility analysis is that they are built on the basis of known welding producibility and cost data. They rely on the existence of Producibility rules and Design for Manufacturing guidelines that contain know-how and knowledge of the limitations of the different materials and welding processes in relation to certain product geometries. Nonetheless, this information about welding capabilities is rarely available as discussed in $[8,11,30]$. The reason is that the welding process output, the quality obtained after the welding process, depends on the interaction of a large number of factors (including welding process parameters, welding set-up configurations, welding fixtures, type of materials and design parameters). Consequently, one of the main problems when considering welding produciblity during design is that the quality obtained after the welding process, defined as welding process capability, varies depending on the product geometry to be welded.

In the case of highly functional integrated products, such as aircraft components, the coupling between product geometry and welding process quality is stronger. The functional requirements of these types of components are satisfied by one integral and continuous physical structure [31]. A slight change in final geometry can have a strong effect on product performance. Thus, the coupling between product geometry and welding output raises the need for studying the interaction and sensitivity coefficients between design and welding parameters. Manufacturability indexes might be good for comparing designs but do not provide information about what level of quality is achieved after welding certain designs.
Therefore, there is a need to model the interaction and study the relationships between design parameters and welding quality in the early phases of the design process. Furthermore, there is a need to complete the Multidisciplinary Design Optimization (MDO) process using automated producibility evaluations that can predict the welding quality output of a large number of design variants of aircraft components.

\section{Approach for evaluating welding- producibility in an industrial MDO environment}

This section begins by providing a description of the industrial product development context in which the automated and interactive welding producibility evaluations must fit in, i.e an industrial Multidisciplinary Design Optimization (MDO) environment. From the description of the MDO environment working principles, gaps to conduct welding producibility analysis are identified. Thereafter, with the objective of filling these gaps, an approach is proposed to conduct welding producibility evaluations in an automated and interactive manner.

\subsection{Automated and interactive industrial MDO environment-Identifying gaps}

The research presented in this paper has been conducted in collaboration with an aerospace company, GKN Aerospace Sweden AB, producing structural components for aircraft engines. The company has developed an automated engineering environment for performing MDO studies, named Engineering Work Bench (EWB) (see Fig. 1). The MDO environment consists of an engineering platform involving different assessment modules with methods and approaches that have the ability to automatically model different geometrical variants and, to some degree, assess these variants for mechanical functioning, aerodynamic performance and producibility. The format and interfaces within the EWB tools are defined and standardized to enable a seamless transfer of data without the need for interactive human work. The EWB environment includes the main engineering domains necessary for making a preliminary assessment of a design concept. The automation is enabled by EWB elements, including, an aero design tool for the automatic generation of realistic aero volumes, a parametric model in CAD that can represent different variants and automatically update the geometry, or an automatic mesh and analysis tool for mechanical assessment.

Although, there is a challenge to automatically analyze structural mechanical behavior and aerodynamic performance, the least developed area so far is the producibility 


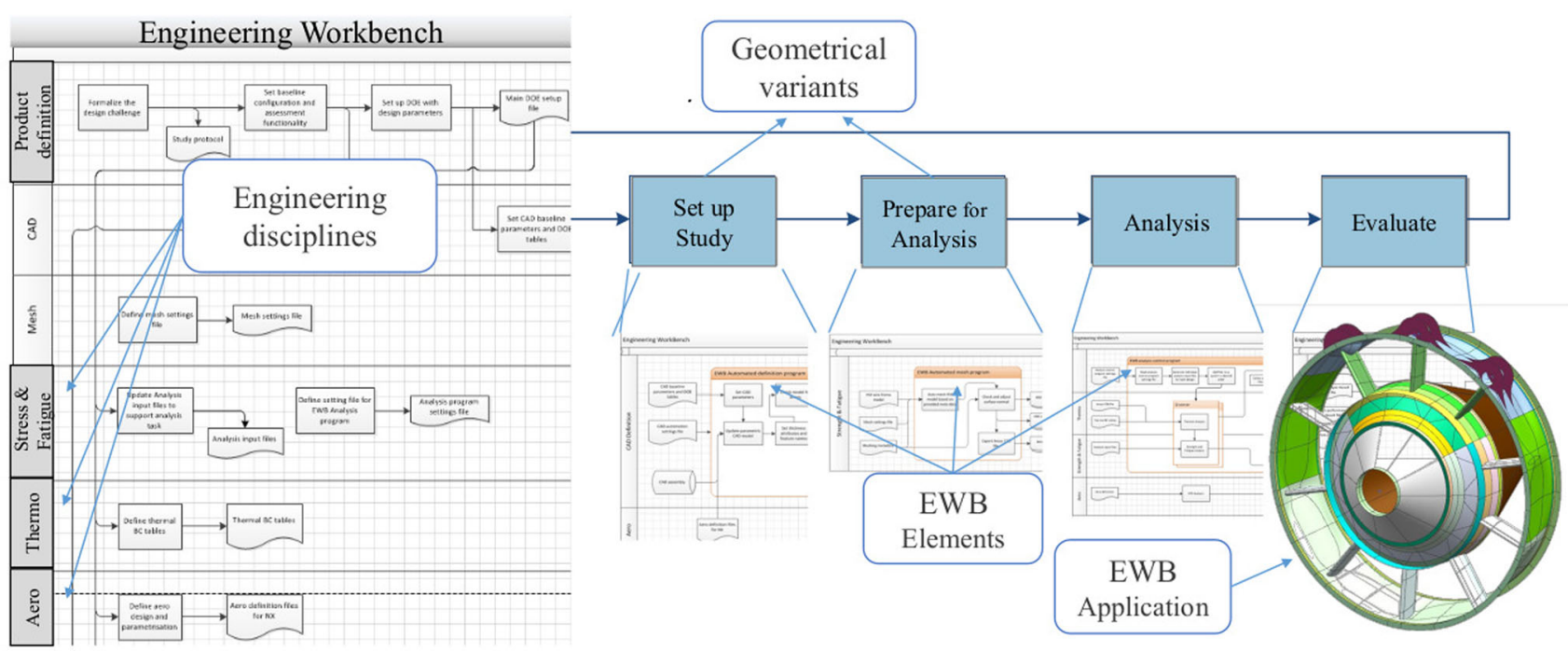

Fig. 1 GKN Aerospace Engineering Work Bench (EWB) environment to enable automated Multidisciplinary Design Optimization

assessment module and the approaches and methods to automatically assess producibility aspects.

It is possible to automate welding simulations to a certain degree. Regarding welding modeling, important advancements have been made to simulate geometrical deformation (distortion) [32-34]. See also software, such as RD\&T® and MSC $($ ). However, not all welding phenomena and welding set-ups can be modeled in existing commercial software. Modeling of cracks and weld bead geometry formation are still in the research stages [35,36]. Recent research studies also cover simulating the effect of welding set-up changes, such as for example different laser welding beam incident angles [10,37].

Welding simulation is not an easy task due to the complex physical phenomena that occur, such as heating, melting and solidification, and the many factors involved. Every new application involves a different product geometry and welding set-up. Thus, modeling conditions change, which may be one reason why, in industry, welding process development still heavily relies on physical testing, which makes the integration of welding analysis within an MDO study tedious, time-consuming and difficult.

Therefore, in order to automatize the process of evaluating a large number of design variants from the producibility discipline, welding simulations must be further developed. However, in some cases, the time for running welding simulations of a large number of design variants is too lengthy. In other cases, the welding phenomena cannot be directly simulated. In these situations, welding simulation can be combined with already built response surface-based models, which are either based on physical testing or simulation (metamodels).
In literature, response surface-based models can be found that predict the effect of welding parameters and their interactions [38-40]. However, most of them do not include the interaction with design parameters, i.e. product geometry.

Based on these gaps, an approach to conduct weldingproducibility evaluations integrated into an automated and interactive MDO environment is proposed. This approach outlines the welding-producibility assessment module, which incorporates welding simulation and response surface-based predictive models that include design parameters with which to perform welding producibility analyses.

\subsection{Approach for welding-producibility evaluations within the MDO environment}

The automated and interactive MDO welding-producibility evaluation approach proposed in this article is governed by four main phases defined within the industrial MDO environment (see Fig. 2). The four phases include:

- (1) Set up study

- (2) Prepare for analysis

- (3) Analyze

- (4) Visualize and Evaluate results

In Fig. 2, each MDO phase has been colored with a different grey tonality. The same color-code has been kept for the specific stages of the different disciplines modules. Examples of discipline modules in Fig. 2 are product definition, aerodynamics, structural mechanics (stress \& fatigue life), cost and welding producibility. 
(1)

(2)

(3)

(4)

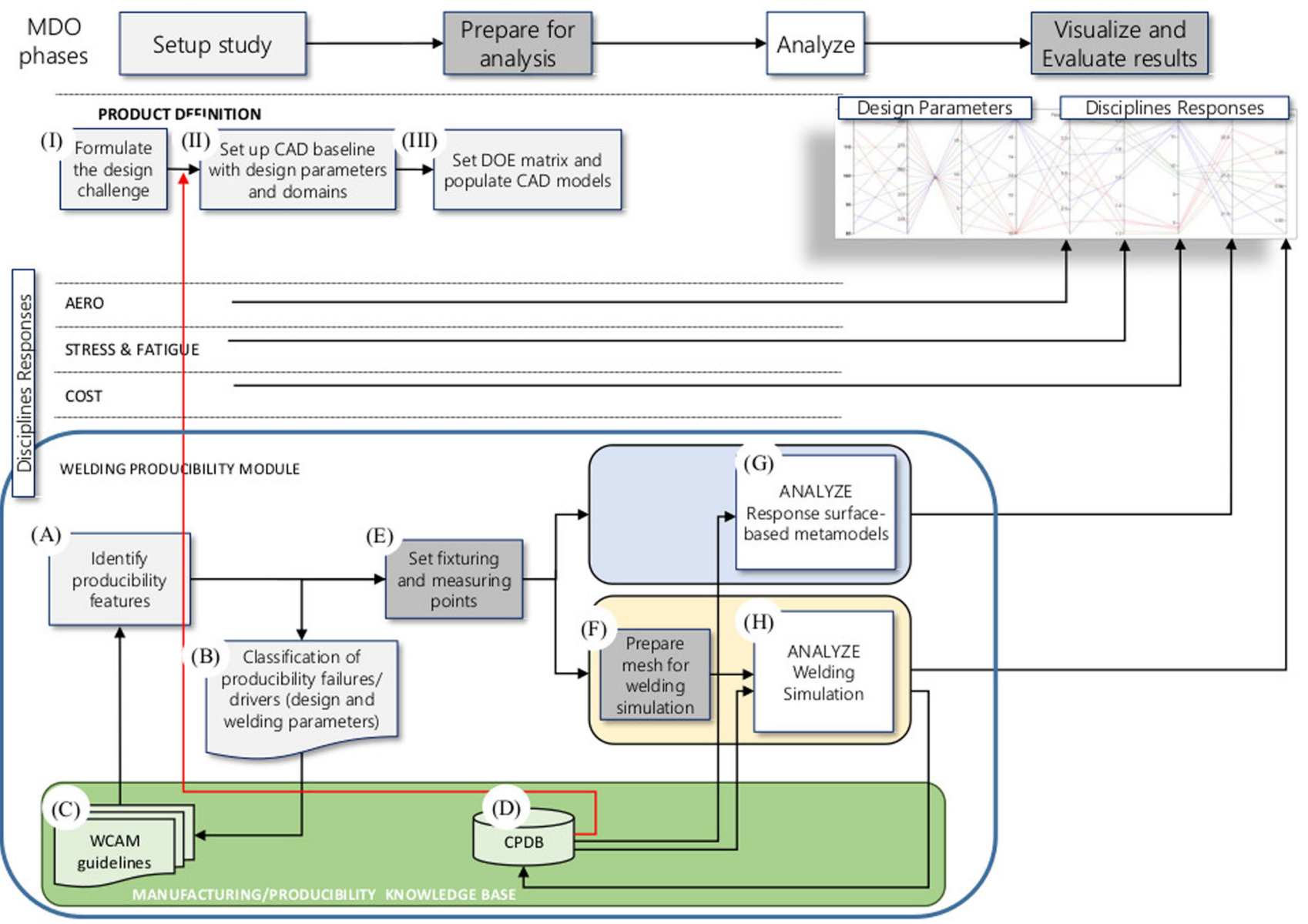

Fig. 2 Automated and interactive MDO welding-producibility assessment module

\subsubsection{MDO Phase (1)—Set up study}

The first phase "(1) Set up study" involves defining the design space and populating it with design variants. First, at the product definition level, the design challenge is formulated, (I)-Fig. 2. During the design challenge formulation, the problem is outlined and possible solutions are discussed to identify which design parameters are important. Conceptual geometries and their potential impact on different disciplines are discussed.

Thereafter, a CAD baseline model is parameterized from which design parameters that would define the design space are derived, (II)-Fig. 2. The range of values of the selected design parameters, i.e. the parameters domain, is set at this stage. These domains serve as input to Design of Experiments (DoE) methods, which are applied to populate the design space with a number of parametric combinations, (III)-Fig. 2.

During this first phase "(1) Set up study", for the weldingproducibility assessment module, producibility features are identified, (A)-Fig. 2, in order to determine producibility constraints to the design space. The objective is to exclude design parametric combinations that do not fulfill already known producibility constraints by limiting the selected design parameter domains.

Producibility features involve producibility failures and their drivers, (B)-Fig. 2. Producibility failures have been previously defined by Madrid et al. [9] as "failures that occur during the manufacturing process caused by the product design in combination with the selected manufacturing solution"(see also [8,9]). A welding producibility failure can occur either when welding output exceeds tolerance limits, i.e. the required quality is not achieved, or when the operation cannot be performed. Examples of producibility failures are accessibility and robot operational matters, geometrical deformation (distortion), in addition to weld discontinuities, such as underfill, lack of joint penetration, cracks and pores.

The producibility drivers of these failures can be combinations of design, welding set-up and welding process parameters. For example, thick joints welded at high speed and low power can lead to joint penetration problems (the material does not fuse throughout the weld depth). 
The Welding Capability Assessment (WCAM) guidelines developed by Madrid et al. [8] provide an extensive description of potential welding producibility failures and their connection to design parameters. In the approach presented in this article, the WCAM guidelines have been incorporated to the producibility assessment module, see (C)-Fig. 2, in order to identify producibility failures and design parameters that contribute to the occurrence of such failures.

In brief, the stages (A)-(B)-(C), Fig. 2, have been designed to identify and connect welding producibility criteria to producibility drivers. It is important to identify the design parameters that, in interaction with welding parameters, can cause producibility problems, thus inhibiting the achievement of the required welding quality levels.

After identification, stored data and information about the effect of design and welding parameters on welding quality output can be employed to derive producibility constraints and limit the design parameter domains that define the design space, before populating it in step (II)-Fig. 2. Designers can automatically connect to the welding CaPability Data Base (CPDB), (D)-Fig. 2. This situation is represented by a red arrow in Fig. 2. The CPDB within the producibility knowledge base, (D)-Fig. 2, contains the welding producibility constraints data and information. This information can take the form of trade-off curves, rules based on expert knowledge, experimental data and response surface-based models. In this way, the design variants (parametric combinations) that are known to be unfeasible are kept out.

Once the different design parameter domains within the design space have been defined by constraints derived from all disciplines, it is time to populate the design space employing the Latin hypercube sampling method, (III)Fig. 2. According to Montgomery [41], this space-filling DoE method is appropriate for computer simulation experiments because the method spreads the design experimental points (design variants) out evenly and uniformly throughout the region of experimentation (the design space).

The DoE matrix obtained after having applied the Latin hypercube method contains all the design variants (parametric combinations) to be analyzed.

From the DoE matrix, context models can be automatically generated for each design variant, (III)-Fig. 2. A context model is a model that is dependent on the type of analysis to be executed, e.g. a CAD model of the section to be welded including fixturing points for producibility analyses, a shell model for initial mechanical assessment and an aero volume for analyzing aerodynamic performance metrics. Thereafter, these context models are analyzed at each discipline assessment module.

\subsubsection{MDO phase (2)—prepare for analysis}

This MDO phase prepares each context model for the specific analyses that will be conducted in each discipline module.

Within the producibility module, the first step is to set fixturing and measuring points, (E)-Fig. 2. Fixturing points reflect how the parts are going to be placed in the fixture during welding in order to ensure adequate alignment conditions. By adding these tagged data to the context model, it is possible to automate the meshing process ((F)-Fig. 2$)$, as well as the welding simulation analysis ((H)-Fig. 2).

\subsubsection{MDO phase (3)—analyze}

During the Analyze-phase, the design variants are analyzed from various engineering disciplines, such as aerodynamics, structural mechanics or producibility. These analyses are performed iteratively since the effect of product geometry into the different discipline responses is coupled due to the integrated nature of these components.

The analyses proposed within the producibility discipline assessment module are divided into two groups: analysis using already built response surface-based predictive models (including metamodels), (G)-Fig. 2, and analysis using welding simulation, (H)-Fig. 2.

Before starting the MDO study, separate investigations can be conducted to create response surface-based predictive models that estimate the effect of design and welding parameters and their effect on welding quality responses. For example, Madrid et al. [10] conducted a Computer Design of Experiment study to model the effect of joint thickness, beam incident angle, welding speed and power on weld bead geometrical quality. Welding simulations were performed to build the predictive model. This metamodel has been utilized in the case study presented in Sect. 3.

The mathematical equation of the response surface-based metamodel can be extracted from the CPDB to automatically predict the welding quality response value (for example, the weld bead geometry) of the design variants included in the DoE matrix, (G)-Fig. 2.

In general, predictive models can be stored in a Capability Data Base (CPDB), (D)-Fig. 2, to be utilized in future MDO studies.

However, there are welding quality responses for which it is difficult to create response surface-based models that can be utilized from case to case. An example is the geometrical deformation (distortion) response. Geometrical deformation in welded components is a consequence of the distortion caused by the melting and solidification phenomena that occur during the welding process. Unlike weld bead geometry, which depends to a large extent on joint thickness, geometrical deformation (distortion) can be caused by product geometry as a whole, thus many design parameters. 
Therefore, geometrical deformation results can vary from product case to case, making it difficult to build response surface-based predictive models. In this case, welding simulations need to be conducted for each of the design variants, (H)-Fig. 2.

\subsubsection{MDO phase (4)—visualize and evaluate results}

In the last step of the MDO study, graphs, such as parallel coordinates and scatter plots, can be employed to visualize the results and evaluate trade-offs between all disciplines including producibility. Interacting with these graphs helps to gain an understanding on how data relate to each other for the purpose of multi-parameter analysis.

In the first place, the goal is to visualize directly the multiparameter data sets and interact with the data to understand correlations, i.e. how the different values of the design parameters constituting the design space can interact and have an effect on different discipline responses.

Besides understanding interactions and effects, the information obtained can serve to either design a new and more detailed MDO study or eliminate certain regions of the design space that became unfeasible, or rank the design variants according to quality levels. Thereafter, in a more detailed evaluation phase, the analysis results from each discipline can be employed to build predictive models based on response surfaces. These response surface-based models can be employed for multidisciplinary optimization since they describe the effect of design parameters on the different engineering discipline responses. In this way, the value of many other parametric combinations within the design space can be predicted. Response surface-based models can be employed to create Pareto Curves in order to perform trade-off studies. Pareto Curves can provide an understanding of how different objectives can be traded against each or relate to each other [42]. Optimization analysis can then be conducted by either weighting each response and optimizing to one objective or by multi-objective optimization (Pareto optimization). To finalize, the producibility knowledge-base proposed in this approach (see green area in Fig. 2) accommodates the WCAM guidelines, (C)-Fig. 2 and the CPDB, (D)-Fig. 2. Both databases are alive and can be fed with the results from the producibility analyses in every MDO study (as expressed in Fig. 2).

\section{Industrial case study}

The automated and interactive approach to perform producibility analyses during the multidisciplinary design process of integrated and welded aerospace components has been validated by a Case Study conducted at our industrial partner. A specific aircraft engine component, the Turbine

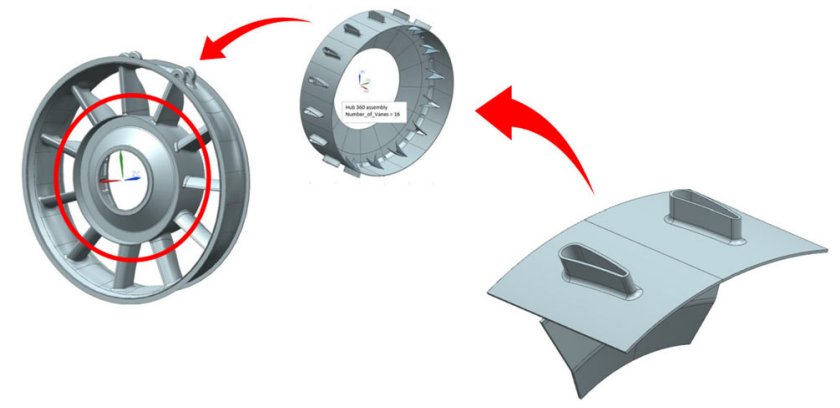

Fig. 3 Hub fabrication in a Turbine Rear Structure (TRS)

Rear Structure (TRS), has been selected for the Case Study (see Fig. 3).

This component is situated at the rear frame of the engine, in the path of the exhaust gases, where it is exposed to high temperatures during operating conditions (up to $700^{\circ} \mathrm{C}$ ). Tough technical demands are imposed on this component. One of the TRS functionalities is to redirect the gas flow to increase thrust efficiency. At the same time, this component must withstand significant thermal and structural loads. The TRS provides a load-path that connects the engine to the aircraft wing, as well as serving as a load carrier for other systems. Furthermore, the ultimate goal is to design engine components that are light-weight and high performance in order to reduce fuel consumption and emissions.

The fabrication process of this component consists of a number of welding stages. First, the TRS hub, indicated by a red circle in Fig. 3, is built by laser welding a number of hub sectors until reaching the $360^{\circ}$ hub form. Thereafter, Tsectors containing the outer case and TRS vanes are welded to the hub. In this Case Study, the focus has been placed on the first welding stage, hub fabrication through laser welding, as represented in Fig. 3.

\subsection{MDO phase (1)—set up study}

\subsubsection{Formulating the design challenge (I)—Fig. 2}

The Case Study presented in this article is a simplified case designed as a proof of concept to validate the producibility evaluation approach within the automated MDO environment. Two design parameters define the design space: the vane length (v_length) and the radial position of the hub knee point, (hk_radial) (see Figs. 4 and 5). In practice, more design parameters would be included, thus increasing complexity.

The vane length (v_length) is a parameter of interest to designers because it can have a significant impact on several engineering aspects, such as structural mechanical behavior, aerodynamics and weight. 


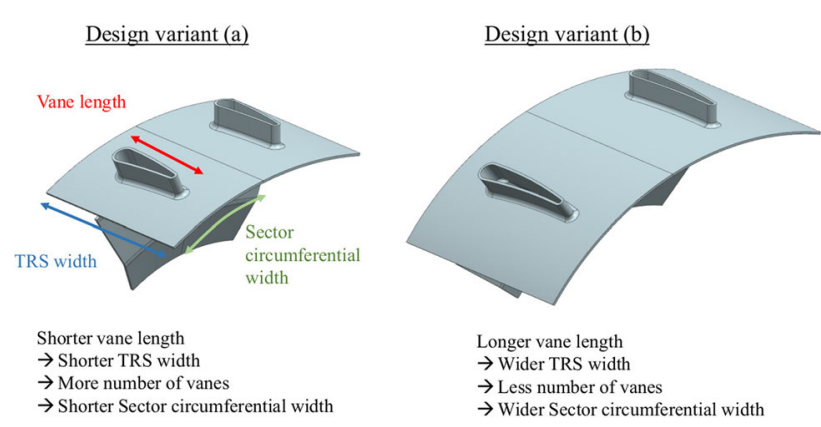

Fig. 4 Two pairs of TRS hub sectors to be welded considering two design variants of the hub sector

For example, the vane length determines the TRS width, as indicated in Fig. 4. Shorter vane lengths allow shorter TRS designs, which in turn allow for shorter engines, i.e. a lighter engines. Furthermore, shorter vanes will require the number of vanes to increase, as the wet surface decreases, to be able to maintain the re-direction of airflow provided by the vanes. The number of vanes will also have an impact on the sector circumferential width, as seen in Fig. 4. More vanes will require shorter sectors to complete the $360^{\circ}$ component.

The second design parameter to include in the MDO study is the so-called "hub knee radial positioN" (hk_radial). In the coordinate system of Fig. 5, the hub knee radial position represents the distance from the center of the TRS to Point 2 on the $\mathrm{Y}$ axis (radial position). In Fig. 5, P1, P2 and P3 symbolize three engine interface points. $\mathrm{P} 2$ represents the hub knee. Due to engine interface requirements, P1 and P3 are locked in the $\mathrm{X}$ and $\mathrm{Y}$ directions whereas $\mathrm{P} 2$ is only locked in the $\mathrm{X}$ direction. These are customer requirements in order for the TRS component to be assembled to the aircraft engine. Thus, the design parameter which designers are interested in controlling is the position of $\mathrm{P} 2$ in the $\mathrm{Y}$ direction, i.e. the hub knee radial position, because it can have an effect on part stiffness.

In Fig. 5, the example of two generic design variants is given. In variant (c), the vane length is shorter and the hub knee radial position is higher if compared to variant (d). In the design variant Fig. 5 (c), the value of the hub knee radial position is such that the "knee" is non-existent if compared to the variant in Fig. 5 (d) in which there is a "knee". The value of the hub knee radial position in the Fig. 5 (c) variant is higher which can result in a higher stiffness value and thus higher stresses if compared to the (d) variant.

\subsubsection{Setting the design space with design parameters and domains (III)-Fig. 2}

The range of values to delimit the 2D design space defined by the vane length and hub knee radial position need to be defined. These design parameter domains serve as input

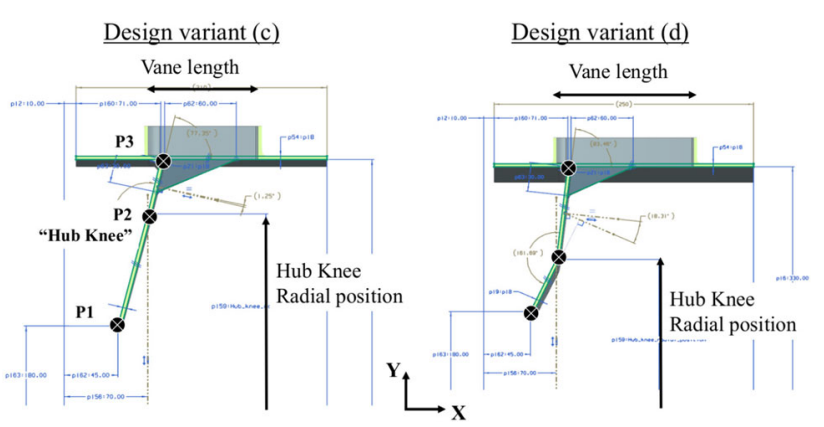

Fig. 5 Two hub sector design variants with different vane lengths and hub knee radial positions

to run the Latin Hypercube method and obtain the DoE matrix containing all design variants. Producibility information about the feasible domains of the different design parameters can be extracted from the producibility database (see (D)-Fig. 2). However, before this step, it is required to identify what type of producibility failures, i.e. weld quality issues, that can be caused by the two design parameters (vane length and hub knee radial position).

\subsubsection{Identifying producibility features (A) —Fig. 2}

The starting point of the approach within the producibility assessment module is the identification of producibility features, (A)-Fig. 2. From the formulation of the design challenge, in which conceptual geometries have been considered and design parameters discussed, the producibility module has the objective of first identifying potential producibility issues that the design might face (the so-called producibility failures) and producibility drivers (design and welding parameters). This identification serves, first, to derive producibility constraints, if information is available, and second, to identify inputs and outputs to the producibility analysis.

In this Case Study, two producibility failures has been identified (joint penetration and geometrical deformationdistortion). A qualitative analysis of the design geometry and its interaction with the selected welding process has been carried out in order to identify these welding producibility failures. This qualitative analysis has been conducted with the support of the WCAM guidelines ((C)-Fig. 2). These guidelines provide an extensive description of potential welding producibility failures and their connection to design parameters. Find the WCAM guidelines in [8].

Joint penetration failure: The hub knee radial position can lead to an operational robot limitation because it implies a curvature due to a radius on the welding interface profile (see Fig. $5 \& 6$ ). This welding robot limitation may cause joint penetration problems, i.e. the metal might not be completely fused throughout the joint thickness. This operational robot 


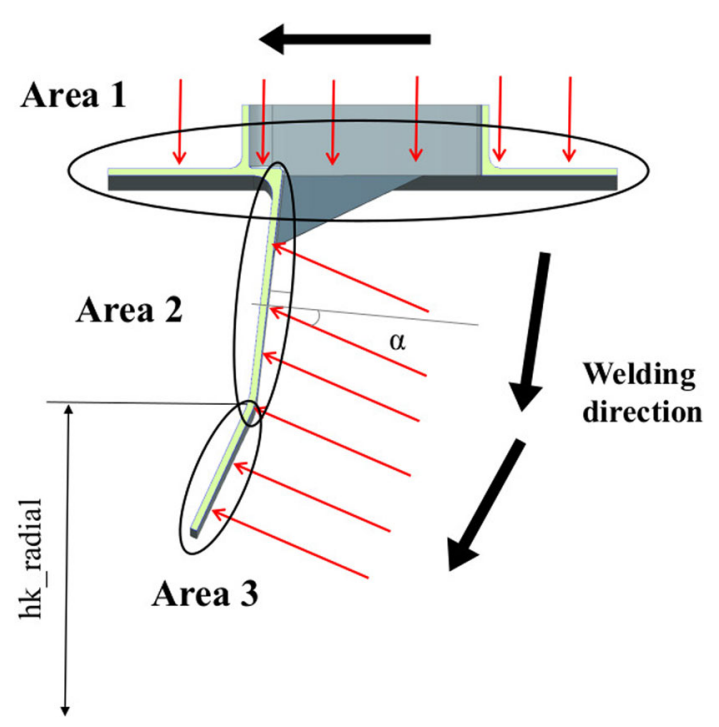

Fig. 6 Welding direction and areas. The red arrows illustrate the laser beams directions, which are related to the laser robot gun position

limitation and joint penetration failures can be derived from the WCAM guidelines, (C)-Fig. 2.

The welding path can be divided into three weld areas, as described in Fig. 6. The red arrows in Fig. 6 represent the laser beams. The first weld area is welded from above, which does not imply any operational limitation. Thus, in this area, the robot and weld gun can adopt the normal position (laser beam perpendicular to the weld interface).

The second and third areas are welded continually, i.e. the welding robot does not stop. In this particular case, the robot cannot adopt the normal position in both areas at the same time as it performs the sharp curve due to robot stability issues during rotation. Thus, the preferred way to perform the weld in Areas 2 and 3 is to maintain the welding robot and gun in the same position along the weld interface curvature (i.e. along Areas 2 and 3, see Fig. 6). In this situation, the laser beams become parallel along Areas 2 and 3 .

Therefore, to overcome the operational robot limitation, the laser welding gun starts with an inclination in Area 2, causing the laser beam to strike with an angle $\alpha$, to maintain the welding gun position and allow Area 3 to be welded using a laser beam perpendicular to the surface.

Depending on the value of the design parameter (hub knee radial position), the beam incident angle $\alpha$ will vary in Area 2 of the weld path. Fig. 7 shows two design variants with different hub knee radial positions (hk_radial), thus causing different laser beam incident angles ( $\alpha=10.6 \circ$ and $\alpha=18.3 \circ$ ).

Welding with a laser beam that is not perpendicular to the welding surface can cause quality problems (producibility failures) related to joint penetration and weld bead bottom width (defined by $\mathrm{C}$ in Fig. 8).

Incomplete joint penetration occurs when the intended weld depth has not been reached, thus showing a visible

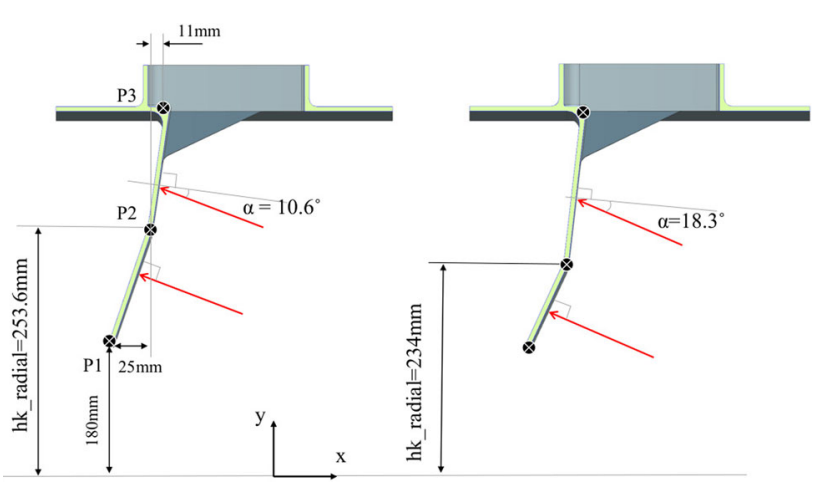

Fig. 7 Scheme for the trigonometrical analysis to obtain the producibility constrain from the operational robot limitation and join penetration failures

gap on the root side of the weld. The reason why the beam incident angle $\alpha$ can cause quality problems related to joint penetration and weld bead bottom width is because welding with a beam incident angle $\alpha$ implies welding thicker material than the nominal joint thickness. In addition, the larger the angle $\alpha$, the more laser rays are reflected, resulting in less heat is concentrated to melt the material. These phenomena, among others, can hinder the material from melting all the way through the joint thickness, which might imply not reaching the requirements of minimum weld bead bottom width. This discontinuity can be considered one of the most severe due to its repair cost. To repair this failure, the welded component must be cut up and a completely new weld must be performed. In addition, tight requirements are set on the weld width $\mathrm{C}$ due to stress analysis on fatigue load calculations to ensure fatigue life and safety requirements. In the TRS component considered in this Case Study, there is a requirement of the minimum value of the weld bead bottom width $\mathrm{C}$ to ensure that the weld does not break under operating conditions.

$C \geq 2 m m$

Thus, the producibility question of designers may be: which hub knee radial position values will cause the robot to weld with beam incident angles that will not fulfill the weld bead bottom width requirement $(\mathrm{C} \geq 2 \mathrm{~mm})$ ?. Finding the maximum angle $(\alpha)$ with which the robot can weld while still fulfilling joint penetration requirements means finding the welding producibility constraint on the design space defined by the hub knee radial position.

In a previous research study, see [10], a metamodel was developed to predict the value of the weld bead bottom width (C) (penetration quality failure) based on a given joint thickness and beam incident angle values. This metamodel represents a form of process capability information (producibility knowledge) that is stored in the Capability Process Data Base (CPDB), see (D)-Fig. 2. 


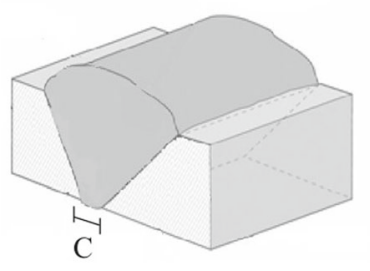

Joint Penetration

(C, weld width)

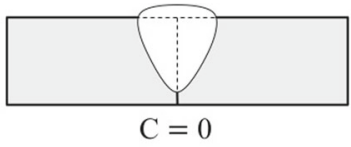

Incomplete joint penetration

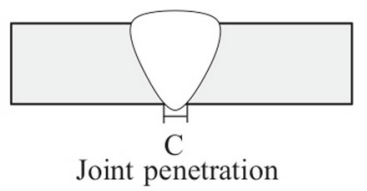

Fig. 8 Producibility failure, joint penetration and weld width, C

The mathematical expression of the predictive metamodel of the weld bead bottom width (C) is given in eq (1), in which $\mathrm{t}[\mathrm{mm}]$ represents the joint thickness, $\alpha^{\circ}$ represents the laser beam incident angle and $\mathrm{P}[\mathrm{W}]$ represents the power (energy) transmitted by the welding equipment.

Metamodel:

$C=0.9-0.62 t-0.096 \alpha+0.002 P$

Welding and design parameters values:

$\mathrm{t}=3 \mathrm{~mm}$

$\mathrm{P}=2339 W$

Producibility constraint, defined by the minimum bottom weld width, see Fig. 8:

$C \geq 2 m m$

According to Eq (1) and considering the welding, design parameter values and the producibility constraint, the maximum $\alpha$ value to ensure sufficient penetrations is:

$\alpha \_\max \leq 19$

The equation relating hk_radial to $\alpha$ after a trigonometric analysis is (see the values given in Fig. 7):

$$
\begin{aligned}
& \alpha=\tan ^{-1}\left(\frac{25}{(\text { hk_radial }-180)}\right)- \\
& \tan ^{-1}\left(\frac{11}{(150-\text { hk_radial }+180)}\right)
\end{aligned}
$$

Thus, the constraint for the design parameter hub knee radial position (hk_radial) can be found according to eq (2) and considering the value of $\alpha \_\max$ :

$h k_{-}$radial $\geq 234 \mathrm{~mm}$

Table 1 Design parameters domains, which delimit the design space

\begin{tabular}{ll}
\hline Design Parameter & Domain \\
\hline Hub Knee Radial position [mm] & $234-281$ \\
Vane length [mm] & $80-120$ \\
\hline
\end{tabular}

Therefore, the domain for the design parameter hub knee radial position that defines the design space is [234-281 mm]. The lower level, $234 \mathrm{~mm}$, is determined by the producibility constraint. The hub knee radial position must be larger or equal to this value in order to fulfill the joint penetration requirement on parameter $\mathrm{C}$. The upper level, $281 \mathrm{~mm}$, is the value that makes the "Knee" disappear making that part completely flat (as can be seen in Fig. 5, Design variant (c)). Geometrical deformation-Distortion failure: During welding, the materials that are melted and solidified expand and contract. These phenomena create shrinkage forces that lead to distortion, i.e. geometrical deformation. The geometrical deformation (distortion) of the hub ring inner-case needs to be kept within tolerances in order not to jeopardize aerodynamics and structure mechanical performance. In this Case Study, a tolerance of $\pm 1.45 \mathrm{~mm}$ is set to the circumference of the TRS hub ring inner-case.

The complete geometry of the parts to be welded can affect the resulting geometrical deformation. Thus, both design parameters, vane length and hub knee radial position, can have an impact on geometrical deformation (distortion).

There are no predictive models relating the design parameters under consideration to geometrical deformation (distortion) in the Manufacturing/Producibility knowledge database. The reason is that geometrical deformation does not depend on isolated design parameters but on the geometry as a whole, so it is difficult to build statistically predictive models for this response. Instead, welding simulations that account for this phenomenon need to be conducted for every new geometrical case, as performed in 4.1.3 (Geometrical deformation/Distortion-Welding simulation (H)-Fig. 2) The design parameters domain considered to form the design space are given in Table 1. The domain for the hub knee radial position is determined by the joint penetration constraint, whereas the vane length value domain is determined by designer choice during the formulation of the Design Challenge.

\subsubsection{Populating the design space-design variants generation (III)-Fig. 2}

Once the domains of the two design parameters that define the design space have been identified (see Table 1), it is time to apply the Latin hypercube sampling method to populate the design space with a number of design variants. The statistical 


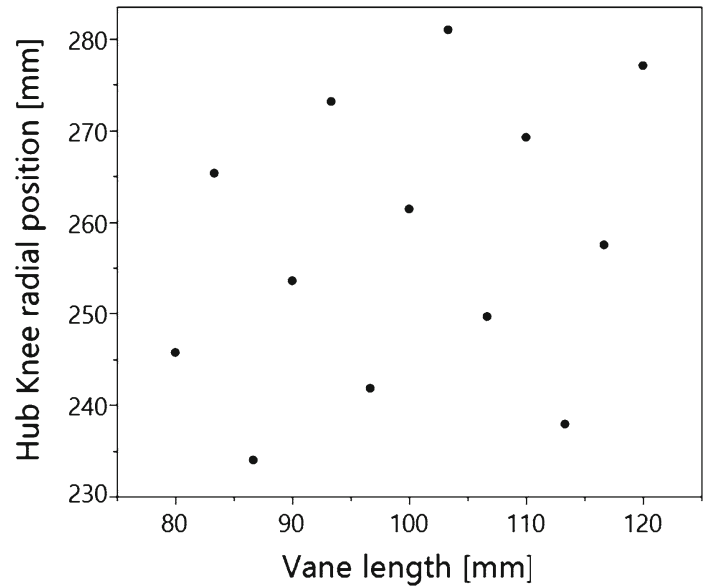

Fig. 9 Design space defined by two design parameters. The dots are representing 13 design variants

software JMP® has been employed for this purpose. Fig. 9 shows the 13 design variants generated and placed in the $2 \mathrm{D}$ design space defined by the two design parameters, hub knee radial position and vane length.

Table 2 shows the 13 design variants in the DoE matrix.

The DoE sampling method, Larin Hypercube, gives the option of selecting the number of experimental points or parametric combinations (i.e. design variants in this context). In this case study, 13 experimental points have been selected. This number can depend on either the resources available (in this context, the time dedicated to the simulation), or the level of detail in which the design space needs to be analyzed (more density of design variants can lead to a richer analysis). In addition, if the purpose is to get a response surface, i.e. to model the effects of the design parameters on the different discipline responses, the number of combinations to be tested would be determined by the type of model to be estimated, i.e. the polynomial degree of the model equation. In this case, a combination of resources, time dedicated to simulation, and desired level of detail led to the selection of 13 parametric combinations that are analyzed in the following sections.

\subsection{MDO phase (2)—prepare for analysis}

This phase within the producibility assessment module focuses on preparing the 13 design variants in order to perform welding simulations to calculate geometrical deformation (distortion).

The preparation for the welding simulation involved the creation of a context model (adequate model to calculate distortion, macro-deformations), a mesh and the definition of fixturing points during welding and releasing stages (see (E)-(F)-Fig. 2).
A parameterized baseline CAD model was created in $\mathrm{NX}$, from which $13 \mathrm{CAD}$ models were generated by changing the values of vane length and hub knee radial position according to Table 2. These solid models were transformed into shell meshes. The hub sectors designed for this Case Study (constant thickness of $3 \mathrm{~mm}$ ) allowed for the use of shell models, thus enabling faster and more simplified welding simulation when compared to solid models.

The shell meshes were designed to include small elements around the welding path $(1 \mathrm{~mm})$ and larger elements (five times larger) in the rest of the model. A fixture design of 3-2-1 was created in the CAD software, Siemens NX® to model the clamping of parts during welding (see fixture points as red arrows in Fig. 10). The 3-2-1 fixture design is a common locating principle with which to constrain the six degrees of freedom in a part [43]. In order to increase automation, a script was created so that the welding simulation software RD\&Tß could automatically read and apply the fixture designs defined in the CAD models.

\subsection{MDO phase (3) -analyze}

The disciplines chosen in this MDO Case study include, structural mechanics (fatigue life-stiffness), weight, cost and producibility. In a real application, there will be other disciplines, such as aerodynamics, that must be considered. However, to simplify our example, only the disciplines mentioned have been included. Furthermore, the contributing focus of this research is on the producibility area. Therefore, greater efforts have been devoted to describing the steps towards conducting a producibility analysis within the MDO study when compared to the other disciplines.

Moreover, the integrated nature that characterizes these types of welded aircraft components require iterative cycles of analyses between disciplines since requirements are coupled. However, the different discipline analyses and their corresponding results are presented in a linear way in the following Sections and in Table 3.

\subsubsection{Producibility analyses}

Two producibility failures have been identified for analysis: joint penetration and geometrical deformation-distortion.

Joint Penetration-Response surface method $(G)$-Fig. 2

The first producibility criterion to be evaluated is joint penetration. This criterion has been defined by the parameter $\mathrm{C}$, weld bead bottom width (see Fig. 8). A response surface-based metamodel has been employed to limit the generation of design variants according to the requirement of $\mathrm{C}(\mathrm{C} \geq 2 \mathrm{~mm})$, see Sect. 3.2. Thus, all 13 design variants that need to be analyzed fulfill already the minimum requirement of joint penetration. However, by making use of the metamodel, the weld bead bottom width value of the 13 vari- 
Table 2 DoE matrix with the 13 design variants

\begin{tabular}{lll}
\hline Design Variant (DV) & Vane length $[\mathrm{mm}]$ & Hub Knee Radial position [mm] \\
\hline DV1 & 113.3 & 237.9 \\
DV2 & 86.7 & 234.0 \\
DV3 & 116.7 & 257.5 \\
DV4 & 110.0 & 269.3 \\
DV5 & 93.3 & 273.2 \\
DV6 & 120.0 & 277.1 \\
DV7 & 100.0 & 261.4 \\
DV8 & 96.7 & 241.8 \\
DV9 & 90.0 & 253.6 \\
DV10 & 83.3 & 265.3 \\
DV11 & 80.0 & 245.8 \\
DV12 & 106.7 & 249.7 \\
DV13 & 103.3 & 281.0 \\
\hline
\end{tabular}

Table 3 MDO study. Analyze phase results

\begin{tabular}{|c|c|c|c|c|c|c|c|c|c|}
\hline & $\begin{array}{l}\text { Control } \\
\text { param } \\
\text { (design }\end{array}$ & $\begin{array}{l}\text { design } \\
\text { eters } \\
\text { space) }\end{array}$ & $\begin{array}{l}\text { Welding } \\
\text { parame- } \\
\text { ter }\end{array}$ & $\begin{array}{l}\text { Design } \\
\text { parame- } \\
\text { ter }\end{array}$ & \multicolumn{2}{|c|}{ Producibility } & \multirow{2}{*}{$\begin{array}{c}\text { Cost } \\
\\
\text { Total } \\
\text { Welding } \\
\text { Time } \\
\text { [min] }\end{array}$} & \multirow{2}{*}{$\begin{array}{c}\text { Weight } \\
\text { Mass } \\
{[\mathrm{kg}]}\end{array}$} & \multirow{2}{*}{$\begin{array}{c}\begin{array}{c}\text { Structural } \\
\text { mechanics }\end{array} \\
\begin{array}{c}\text { Stiffness } \\
\text { Normal- } \\
\text { ized }\end{array}\end{array}$} \\
\hline $\begin{array}{c}\text { Design } \\
\text { Variants } \\
(\mathrm{DV})\end{array}$ & $\begin{array}{l}\text { V_length } \\
{[\mathrm{mm}]}\end{array}$ & $\begin{array}{l}\text { Hk_radial } \\
{[\mathrm{mm}]}\end{array}$ & $\begin{array}{c}\text { Beam } \\
\text { angle } \alpha \\
\left.{ }^{\circ}\right]\end{array}$ & $\begin{array}{l}\text { Number } \\
\text { of Vanes }\end{array}$ & $\begin{array}{c}\text { Penetra- } \\
\text { tion C } \\
{[\mathrm{mm}]}\end{array}$ & $\begin{array}{l}\text { Distor- } \\
\text { tion, } \\
\text { Normal } \\
{[\mathrm{mm}]}\end{array}$ & & & \\
\hline DV1 & 113.33 & 237.92 & 16.54 & 10 & 2.31 & 1.35 & 7.77 & 21.98 & 0.89 \\
\hline DV2 & 86.67 & 234.00 & 18.31 & 16 & 2.14 & 1.52 & 11.59 & 21.24 & 0.83 \\
\hline DV3 & 116.67 & 257.50 & 9.25 & 10 & 3.01 & 1.40 & 7.81 & 22.11 & 0.95 \\
\hline DV4 & 110.00 & 269.25 & 5.38 & 10 & 3.38 & 1.31 & 7.66 & 21.65 & 0.95 \\
\hline DV5 & 93.33 & 273.17 & 4.07 & 13 & 3.51 & 1.63 & 9.53 & 21.08 & 0.92 \\
\hline DV6 & 120.00 & 277.08 & 2.7 & 10 & 3.64 & 1.34 & 7.86 & 22.25 & 1.00 \\
\hline DV7 & 100.00 & 261.42 & 7.96 & 13 & 3.14 & 1.71 & 9.71 & 21.56 & 0.92 \\
\hline DV8 & 96.67 & 241.83 & 14.9 & 13 & 2.47 & 1.66 & 9.66 & 21.41 & 0.86 \\
\hline DV9 & 90.00 & 253.58 & 10.57 & 16 & 2.88 & 1.64 & 11.65 & 21.40 & 0.88 \\
\hline DV10 & 83.33 & 265.33 & 6.68 & 16 & 3.26 & 1.59 & 11.41 & 20.91 & 0.88 \\
\hline DV11 & 80.00 & 245.75 & 13.38 & 16 & 2.61 & 1.50 & 11.34 & 20.74 & 0.83 \\
\hline DV12 & 106.67 & 249.67 & 11.94 & 10 & 2.75 & 1.30 & 7.62 & 21.51 & 0.90 \\
\hline DV13 & 103.33 & 281.00 & 1.25 & 13 & 3.78 & 1.68 & 9.78 & 21.71 & 0.97 \\
\hline
\end{tabular}

ants can be automatically predicted and the variants ranked. The results are shown in Table 3.

\section{Geometrical deformation/Distortion-Welding simulation} (H)-Fig. 2

The second producibility criterion to be evaluated is geometrical deformation (distortion). In this particular Case Study, the geometrical deformation (distortion) in the normal direction has been of interest because normal deformation in the hub sector edges can create a flush, thus compromising the next assembly step (a gap in normal direction between hub sectors to be welded). In addition, the deformation of the hub ring inner-case needs to be kept within tolerance limits to not jeopardize aerodynamics and structure mechanical performance. In this Case Study, a tolerance of $\pm 1.45 \mathrm{~mm}$ is set for the circumference of the TRS hub ring inner-case.
To calculate geometrical deformation (distortion), welding simulations of the 13 design variants have been conducted in RD\&TR software. The results are presented in Table 3.

The welding simulation approach employed has been based on the SCV simulation method described by Lorin et al. [44]. First, the melted zones in each of the three weld areas (see Fig.6) were calculated. Thereafter, the calculated melted zones were applied into a static-elastic simulation to calculate geometrical deformation (distortion).

To obtain the pre-calculated melted zones in the different weld areas, thermal steady-state simulations were conducted on simple plates with the same material and thickness as the original hub sector geometrical model. As studied by Madrid et al. [10], a melted zone shape varies according to the thickness and beam incident angle $(\alpha)$ for the same welding 

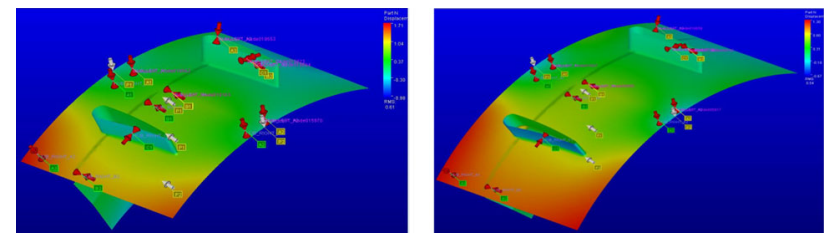

Fig. 10 Geometrical deformation (distortion) in normal direction after welding for design variants 7 and 12

parameters. In this Case Study, the joint thickness is constant in the three weld areas. Thus, melted zones in weld areas $\mathrm{A} 1$ and $\mathrm{A} 3$ are alike because in both areas, there is zero inclination in the laser beam, $\alpha=0^{\circ}$ to the surface. Instead, a new melted zone for weld area A2 needed to be calculated for each of the design variants because the laser beam incident angle $(\alpha)$ value was changed.

To be able to model the effect of the laser beam incident angle, a combined heat source model was employed based on the research presented in $[10,45]$.

The goal of conducting welding simulations employing thermo-dynamical steady-state simulations has been to save computational time. The welding simulation time of a single design variant has been up to $2 \mathrm{~min}$ in this Case Study. As argued in [46-48], steady-state models are fast and can produce acceptable results in a number of cases.

Geometrical deformation (distortion) was calculated at each node for every design variant. Fig. 10 shows, as an example, the geometrical deformation (distortion) in the normal direction for two of the design variants (design variants DV 7 and DV 12). The color scale shows red to indicate the points with high and positive values of geometrical deformation (distortion). The color blue shows the minimum values of geometrical deformation (distortion) in the negative normal direction.

The value of a point with maximum geometrical deformation (distortion) in the normal direction has been measured for each design variant (DV) and extracted into a data table (see Table 3, distortion column). For example, in Table 3, DV 7 has a distortion value of $1.71 \mathrm{~mm}$, which lies outside tolerance limits. Instead, DV 12 has a distortion value of 1.30 $\mathrm{mm}$, which lies within tolerances. This means that DV 7 has a point of greater geometrical deformation in the normal direction than DV 12. However, when looking at red-colored areas in both design variants in Fig. 10, it can be concluded that DV 12 has more points with deformation in the positive normal direction compared to DV 7 since the red area is larger in DV 12.

\subsubsection{Analyses of the other disciplines}

Cost The cost was calculated based on welding time, which in turn was calculated based on the total weld length according to eq 3. The results shown in Table 3 refer to the total cost of welding the whole hub, i.e. the result of welding all sectors into a completely full ring. The evaluating objective is based on the goal of reducing cost.

$$
\text { Cost } \propto \operatorname{Time}[\mathrm{min}]=\frac{\text { total weld length }[\mathrm{mm}]}{\text { welding } \operatorname{speed}[\mathrm{mm} / \mathrm{min}]}
$$

Weight The weight was derived from the mass in the CAD models. The results shown in Table 3 also refer to the total weight of the entire hub. The evaluating objective was based on the goal of making light components.

Structural mechanics (fatigue life-stiffness) The flange of the Hub has been designed with a "Knee" to control the stiffness of the part (see Figs. 4 and 5). Each design variant has a different radial Hub Knee position, thus a different part stiffness. For this type of component the geometry is very significant, which makes the stiffness very important to minimize deformations leading to aero dynamical efficiency losses. A simplified stiffness analysis of the 13 design variants was performed by a mechanical engineer at the industrial partner using a FEM software. Stiffness was calculated as a pre-step before calculating stress and fatigue life of the component. For the purpose of this study, the results presented in Table 3 were normalized due to Intellectual Property matters.

\subsection{MDO phase (4)—visualize and evaluate results-phase}

The results of the analyses within the MDO study have been presented in Table 3. Each row in Table 3 represents a design variant (DV). Thus, there is a total of 13 rows, which correspond to 13 design variants (see Fig. 9 and Table 2. The columns correspond to design and welding parameters, as well as to responses, i.e. the effect on each of the disciplines (producibility, cost, weight and structural mechanics). The first two columns contain the two design parameters that form the design space, i.e. the design parameters designers want to control (vane length and hub knee radial position).

The visualization of the results has been presented in a parallel coordinate graph shown in Fig. 11. The parallel coordinate graph is an interactive tool developed at the industrial partner from an existing Javascript obtained from a free source. Each colored line in the graph represents one of the design variants in Table 3.

The parallel coordinate graph in Fig. 11 serves to visualize, in an interactive manner, how factors and responses (inputs and outputs) relate to each other. The purpose is to interact with the data in order to understand correlations that will support design decisions.

For example, in this study, producibility has been defined as the effect on joint penetration and geometrical deformation 


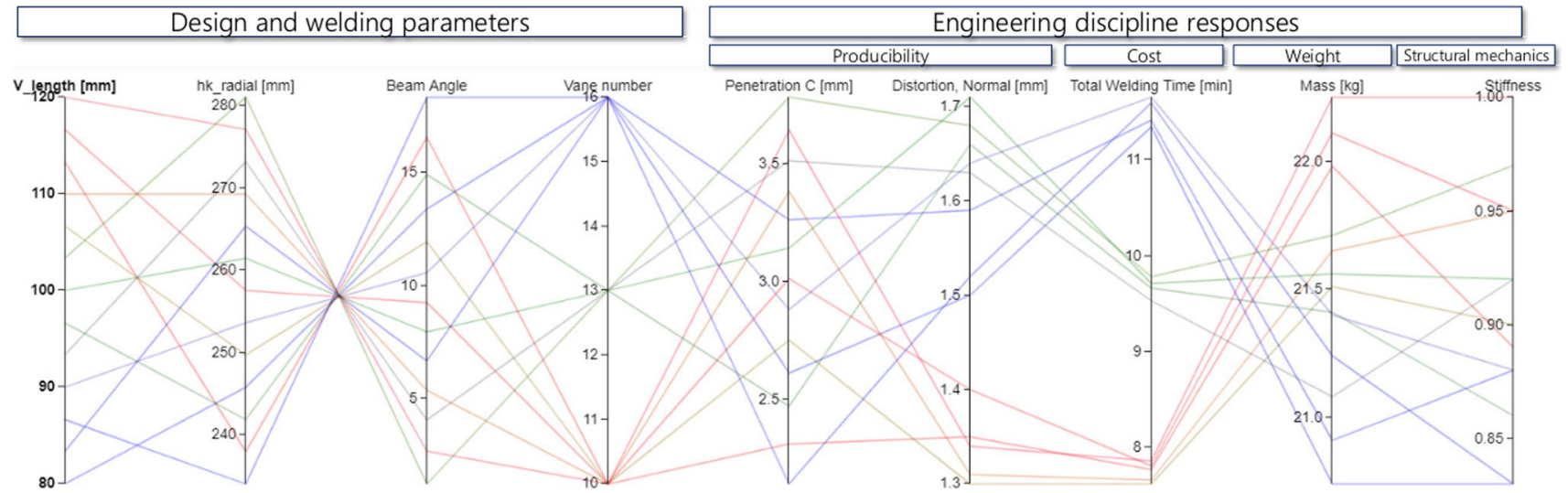

Fig. 11 Parallel coordinate graph visualizing the effect of design and welding parameters in the different engineering discipline responses, according to results in Table 3. Each coloured line represents a design variant

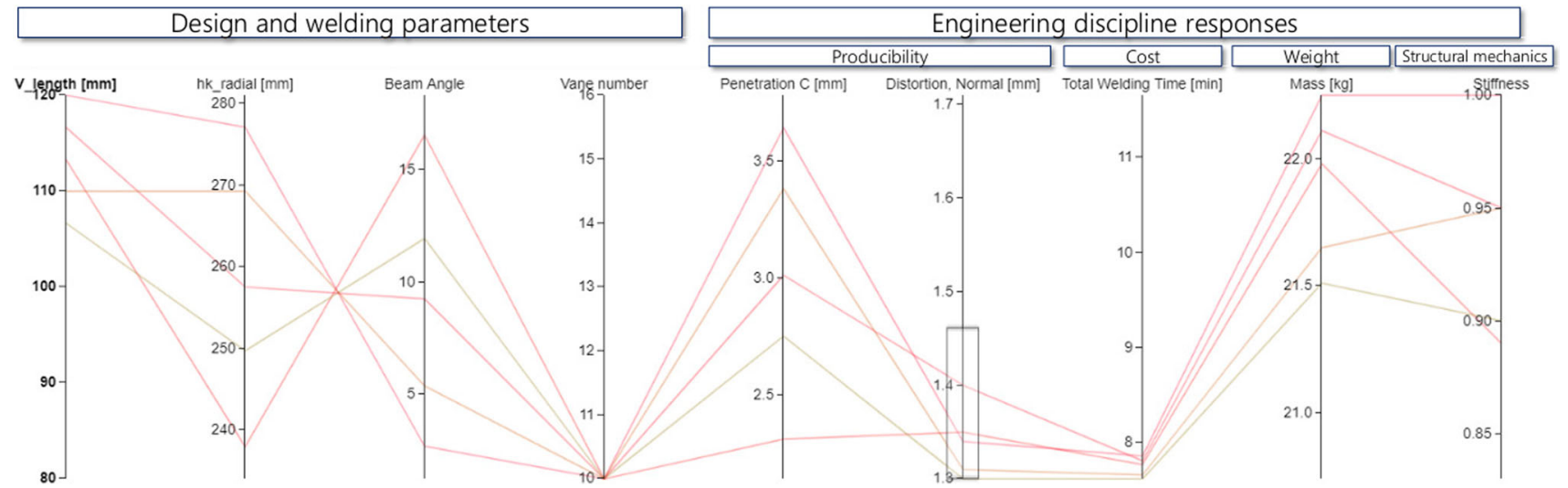

Fig. 12 Parallel coordinate graph showing the resulted design variants from down selecting the design variants with low distortion values

(distortion). All design variants already fulfill the minimum requirement of joint penetration $\mathrm{C} \geq 2 \mathrm{~mm}$ due to the producibility constraint imposed on the design space. Thus, as an example, designers can focus on selecting design variants that result in less geometrical deformation (distortion) in the parallel coordinate graph. The tolerance on geometrical deformation (distortion) has been set to $\pm 1.45 \mathrm{~mm}$, as described in 4.1.3. Thus, the parallel axis corresponding to the geometrical deformation (distortion) dimension can be limited according to this tolerance. The result is shown in Fig. 12, in which 5 lines, i.e. 5 design variants, have been kept after the screening. The 5 design variants represented in Fig. 12 correspond to the 5 rows colored in grey in Table 3.

After this selection-screening, the first interaction that can be visualized in Fig. 12 is the relation between the vane length (v_length design parameter, see Fig. 12) and geometrical deformation (distortion). High values of vane length lead to low geometrical deformation (distortion) values. According to these results, designers can limit the value of the vane length if the main purpose is to lower geometrical deformation (distortion). At the same time, low geometrical deformation (distortion) values lead to low total welding time and middle-high values of weight and stiffness. With this information, designers can, for example, decide to limit the design space, i.e. exclude design variants, in order to obtain either low values of weight or specific values for stiffness.

Therefore, besides understanding interaction and correlation effects, the parallel coordinate graph presented in Fig. 11 and Fig. 12 can assist designers to eliminate regions of the design space containing unfeasible design variants, i.e. variants that will not be able to either be produced or achieve minimum levels of quality.

Another application can be to rank design variants according to specific quality criteria, for example, according to the mass (weight) or according to the distortion and joint penetration values.

In a more detailed evaluation phase, the results from Table 3 can be employed to build response surface-based models for the purpose of performing optimization. Designers can conduct optimization analyses either by weighting each response and optimize into a single objective or by multi-optimization (Pareto optimization). 


\section{Discussion}

The producibility evaluation approach proposed allows designers to systematically evaluate the design space from the producibility discipline. Two screening steps have been described in the approach. First, the design space is constrained by the producibility discipline, which enables designers to keep out all design variants that do not fulfill a particular producibility criterion. Producibility constraints are defined based on information obtained from stored responses surface-based models and producibility rules. Additional constraints can be applied to the design space from other engineering disciplines. After this first screening step, the remaining design variants are then analyzed in a second screening step at each discipline module.

To make this approach adequate for integrated welded aircraft components, it has been important to predict rapidly and virtually the effect of design parameters into welding quality responses. Thus, the analyses proposed in the welding producibility module are based on two methods: Welding simulation and Response Surface method.

Welding simulation allows to conduct analysis on a large number of design variants in shorter time and for lower cost in comparison to physical testing. Modeling welding also provides more extended and detailed information concerning welding phenomena, such as the heat distribution and the relationship to design and welding process parameters, as argued by Goldak [49]. However, welding simulations may need, in some cases, further development to cover all welding phenomena, as discussed by Madrid et al. [10]. Thus, in the case presented in this article, a novel combined heat source model developed in a previous research study (see [10]) has been incorporated into the welding simulation. The objective was to model the effect of welding with various laser beam angles on geometrical deformation (distortion).

A total of 13 welding simulations, one simulation for each design variant, has been conducted to calculate geometrical deformation. However, other welding quality defects, such as weld joint penetration, could be predicted through response-based predictive models. Predictive models can be built in those cases in which the welding quality response only depends on the effect of a few design parameters.

The Response Surface method can generate predictive models based on experimental data (metamodels in the case of computer experiments). These predictive models can be created in separate experimental studies, which offers the opportunity of including the interaction of additional design and welding process parameters. Moreover, predictive models can be stored in the producibility knowledge data base and be reused from application case to case, thus saving time during the MDO analysis processes.

In the Case Study presented, a metamodel has been employed to calculate the joint penetration of 13 design vari- ants. Thus, there was no need to perform 13 new simulations to calculate this response. This metamodel was developed in a separate study, see [10].

Welding simulation and response surface-based models allow designers to predict the welding quality output and increase the automation capabilities of the weldingproducibility analysis process within the MDO environment.

Thereafter, producibility results are evaluated together with the results from other engineering disciplines with the objective of first understanding correlations and second, performing optimization. One of the focuses of this study has been to highlight the importance of interacting with multiparameter data with the support of interactive tools, such as parallel coordinate graphs, in order to understand correlations in support of design decisions.

\section{Conclusions}

During the design process of welded aircraft components, design modifications on product geometry can be conducted in order to improve welding producibility with the objective of reducing weld quality defects and geometrical deformation (distortion) during the welding process. However, due to the integrated nature of this type of welded components, these design modifications can also impact on the aerodynamic performance, structural mechanics behaviour, weight, cost, etc.

Therefore, there is a need to analyze welding producibility together with the other engineering disciplines during the MDO process.

The steps in the MDO process involve defining a design space, populating it with design variants and analyzing these variants from various engineering disciplines to decide upon which design variants should be further developed and optimized.

The aim of this article has been to equip the producibility stakeholder with equivalent tools and approaches as exist within the fields of mechanical engineering and computational fluid dynamics in order to achieve similar levels of automated and virtual analysis. In this paper, an approach to conduct welding-producibility evaluations within the context of an automated and interactive Multidisciplinary Design Optimization (MDO) environment has been proposed. The approach has been validated in an industrial case study. The proposed approach enables designers to generate and reuse welding producibility information to perform analyses of a big spectrum of the design space in a rapid and interactive fashion, thus supporting designers in dealing with change and making fact-based decisions during the multidisciplinary design process of integrated aerospace components. 
Funding Open access funding provided by Chalmers University of Technology.

Open Access This article is licensed under a Creative Commons Attribution 4.0 International License, which permits use, sharing, adaptation, distribution and reproduction in any medium or format, as long as you give appropriate credit to the original author(s) and the source, provide a link to the Creative Commons licence, and indicate if changes were made. The images or other third party material in this article are included in the article's Creative Commons licence, unless indicated otherwise in a credit line to the material. If material is not included in the article's Creative Commons licence and your intended use is not permitted by statutory regulation or exceeds the permitted use, you will need to obtain permission directly from the copyright holder. To view a copy of this licence, visit http://creativecomm ons.org/licenses/by/4.0/.

\section{References}

1. Marcus, S., Ilya, T., Michael, K., Lundbladh, A., Isaksson, O.: A knowledge-based master model approach exemplified with jet engine structural design. Comput. Ind. 85, 31-38 (2017)

2. Müller, J. R., 2018. Towards automated conceptual design space exploration. Licentiate thesis, Chalmers University of Technology

3. Berrezzoug, S., Boudjemai, A., Bendimerad, F.T.: Interactive design and multidisciplinary optimization of geostationary communication satellite. Int. J. Interact. Des. Manuf. (IJIDeM) 13(4), 1519-1540 (2019)

4. Ali, F., Tzanidakis, K., Goulos, I., Pachidis, V., dIppolito, R.: Design space exploration and optimization of conceptual rotorcraft powerplants. J. Eng.Gas Turb. Power 137(12),(2015)

5. Simpson, T.W., Poplinski, J., Koch, P.N., Allen, J.K.: Metamodels for computer-based engineering design: survey and recommendations. Eng. comput. 17(2), 129-150 (2001)

6. Rabeau, S., Dépincé, P., Bennis, F.: Collaborative optimization of complex systems: a multidisciplinary approach. Int. J. Interact. Des. Manuf. (IJIDeM) 1(4), 209-218 (2007)

7. Unal, M., Warn, G.P., Simpson, T.W.: Quantifying the shape of pareto fronts during multi-objective trade space exploration. J. Mech. Des. 140(2), 021402 (2018)

8. Madrid, J., Forslund, A., Söderberg, R., Wärmefjord, K., Hoffenson, S., Vallhagen, J., Andersson, P.: A welding capability assessment method (wcam) to support multidisciplinary design of aircraft structures. Int. J. Interact. Des. Manuf. (IJIDeM) 12(3), 833-851 (2018)

9. Madrid, J., Landahl, J., Söderberg, R., Johannesson, H., and Lööf, J., 2018. Mitigating risk of producibility failures in platform concept development. In Proceedings of the 31st Congress of the International Council of the Aeronautical Sciences, Belo Horizonte, Brazil, pp. 9-14

10. Madrid, J., Lorin, S., Söderberg, R., Hammersberg, P., Wärmefjord, K., Lööf, J.: A virtual design of experiments method to evaluate the effect of design and welding parameters on weld quality in aerospace applications. Aerospace 6(6), 74 (2019)

11. Madrid, J., Vallhagen, J., Söderberg, R., Wärmefjord, K.: Enabling reuse of inspection data to support robust design: a case in the aerospace industry. Procedia CIRP 43, 41-46 (2016)

12. Saxena, T., and Karsai, G., 2010. Towards a generic design space exploration framework. In 2010 10th IEEE International Conference on Computer and Information Technology, IEEE, pp. 1940-1947
13. Kang, E., Jackson, E., Schulte, W.: An approach for effective design space exploration, pp. 33-54. Springer, In Monterey Workshop (2010)

14. Sandberg, M., Tyapin, I., Kokkolaras, M., Isakasson, O., Aidanpää, J.-O., Larsson, T.: A knowledge-based master-model approach with application to rotating machinery design. Concurr. Eng. 19(4), 295305 (2011)

15. Pronzato, L., Müller, W.G.: Design of computer experiments: space filling and beyond. Stat. Comput. 22(3), 681-701 (2012)

16. Zutta, E., Acosta, D., Duque, A., Diaz, A.: Development of simulation metamodels to predict the performance and exhaust emission parameters of a spark ignition engine. Int. J. Interact. Des. Manuf. (IJIDeM) , 1-12 (2019)

17. Cunningham, J.D., Simpson, T.W., Tucker, C.S.: An investigation of surrogate models for efficient performance-based decoding of 3d point clouds. J. Mech. Des. 141(12),(2019)

18. Sandberg, M., Design for manufacturing: methods and applications using knowledge engineering. PhD thesis, Luleå tekniska universitet (2007)

19. Elgh, F., Computer-supported design for producibility: principles and models for system realisation and utilisation. $\mathrm{PhD}$ thesis, Chalmers University of Technology (2007)

20. Elgh, F., Cederfeldt, M.: Cost-based producibility assessment: analysis and synthesis approaches through design automation. J. Eng. Des. 19(2), 113-130 (2008)

21. Khodaygan, S.: An interactive method for computer-aided optimal process tolerance design based on automated decision making. Int. J. Interact. Des. Manuf. (IJIDeM) 13(1), 349-364 (2019)

22. Söderberg, R., Tolerance allocation in a cad enviroment considering quality and manufacturer cost. In Proceedings of Lean Production: from Concept to Product Conference, IMC-11 Belfast 31 August-2 September, Vol. 2, pp. 789-800 (1994)

23. Tzivelekis, C.A., Yiotis, L.S., Fountas, N.A., Krimpenis, A.A.: Parametrically automated $3 \mathrm{~d}$ design and manufacturing for spiraltype free-form models in an interactive cad/cam environment. Int. J. Interact. Des. Manuf. (IJIDeM) 11(2), 223-232 (2017)

24. Shah, J.J., Mäntylä, M.: Parametric and feature-based CAD/CAM: concepts, techniques, and applications. Wiley, Hoboken (1995)

25. Hoefer, M., Chen, N., and Frank, M., 2017. Automated manufacturability analysis for conceptual design in new product development. In IIE Annual Conference. Proceedings, Institute of Industrial and Systems Engineers (IISE), pp. 860-865

26. Zhang, Y., Yang, S., Zhao, Y.F.: Manufacturability analysis of metal laser-based powder bed fusion additive manufacturing-a survey. Int. J. Adv. Manuf. Technol. 110(1), 57-78 (2020)

27. Maropoulos, P., Yao, Z., Bradley, H., Paramor, K.: An integrated design and planning environment for welding: Part 1: Product modelling. J. Mater. Proc. Technol. 107(1-3), 3-8 (2000)

28. Chayoukhi, S., Bouaziz, Z., Zghal, A.: Costweld: a cost estimation system of welding based on the feature model. Adv. Prod. Eng. Manag. 4(4), 263-274 (2009)

29. Stolt, R., André, S., Elgh, F., Andersson, P.: Introducing welding manufacturability in a multidisciplinary platform for the evaluation of conceptual aircraft engine components. Int. J. Prod. Lifecyc. Manag. 10(2), 107-123 (2017)

30. Ibrahim, I.H., Chassapis, C.: An interactive variation risk management environment to assess the risk of manufacturing variations. Int. J. Interact. Design Manuf. (IJIDeM) 11(3), 597-608 (2017)

31. Raja, V., Johannesson, H., Isaksson, O.: Describing and evaluating functionally integrated and manufacturing restricted product architectures. Res. Eng. Des. 29(3), 367-391 (2018)

32. Pahkamaa, A., Wärmefjord, K., Karlsson, L., Söderberg, R., Goldak, J.: Combining variation simulation with welding simulation for prediction of deformation and variation of a final assembly. J. Comput. Inf. Sci. Eng. 12, 2 (2012) 
33. Lindgren, L.-E.: Modelling for residual stresses and deformations due to welding: knowing what isn't necessary to know. In International Seminar on Numerical Analysis of Weldability: 01/10/2001-02/10/2001, Maney Publishing (for The Institute of Materials, Minerals and Mining), pp. 491-518 (2002)

34. Lindgren, L.-E., Lundbäck, A., Malmelöv, A.: Thermal stresses and computational welding mechanics. J. Therm. Stress. 42(1), 107-121 (2019)

35. Draxler, J., Edberg, J., Andersson, J., Lindgren, L.-E.: Modeling and simulation of weld solidification cracking part i. Weld. World 63(5), 1489-1502 (2019)

36. Hernando, I., Arrizubieta, J.I., Lamikiz, A., Ukar, E.: Numerical model for predicting bead geometry and microstructure in laser beam welding of inconel 718 sheets. Metals 8(7), 536 (2018)

37. Kumar, N., Mukherjee, M., Bandyopadhyay, A.: Study on laser welding of austenitic stainless steel by varying incident angle of pulsed laser beam. Opt. Laser Technol. 94, 296-309 (2017)

38. Caiazzo, F., Alfieri, V., Sergi, V., Schipani, A., Cinque, S.: Dissimilar autogenous disk-laser welding of haynes 188 and inconel 718 superalloys for aerospace applications. Int. J. Adv. Manuf. Technol. 68(5-8), 1809-1820 (2013)

39. Benyounis, K., Olabi, A.-G.: Optimization of different welding processes using statistical and numerical approaches-a reference guide. Adv. Eng. Softw. 39(6), 483-496 (2008)

40. Nagaraju, U., Gowd, G.H., Vardan, T.V.: An integrated approach for optimization of pulsed nd: Yag laser beam welding process. Mater. Today Proceed. 5(2), 7991-8000 (2018)

41. Montgomery, D.C.: Design and analysis of experiments. Wiley, Hoboken (2017)

42. Mack, Y., Goel, T., Shyy, W., and Haftka, R.: Surrogate modelbased optimization framework: a case study in aerospace design. In Evolutionary computation in dynamic and uncertain environments. Springer, pp. 323-342 (2007)
43. Söderberg, R., Lindkvist, L.: Computer aided assembly robustness evaluation. J. Eng. Des. 10(2), 165-181 (1999)

44. Lorin, S., Cromvik, C., Edelvik, F., Lindkvist, L., Söderberg, R.: Variation simulation of welded assemblies using a thermo-elastic finite element model. J. Comput. Inf. Sci. Eng. 14(3),(2014)

45. Lorin, S., Madrid, J., Söderberg, R., Wärmefjord, K.: A new heat source model for keyhole mode laser welding. J. Comput. Inf. Sci. Eng. 22(1), 011004 (2021)

46. Tsirkas, S., Papanikos, P., Kermanidis, T.: Numerical simulation of the laser welding process in butt-joint specimens. J. Mater. Proc. Technol. 134(1), 59-69 (2003)

47. Lorin, S., Cromvik, C., Edelvik, F., Lindkvist, L., Söderberg, R., and Wärmefjord, K., 2014. Simulation of non-nominal welds by resolving the melted zone and its implication to variation simulation. In ASME 2014 International Design Engineering Technical Conferences and Computers and Information in Engineering Conference, American Society of Mechanical Engineers Digital Collection

48. Lorin, S., Cromvik, C., Edelvik, F., Lindkvist, L., and Söderberg, R., 2014. On the robustness of the volumetric shrinkage method in the context of variation simulation. In ASME 2014 International Mechanical Engineering Congress and Exposition, American Society of Mechanical Engineers Digital Collection

49. Goldak, J.A., Akhlaghi, M.: Computational welding mechanics. Springer, NewYork (2006)

Publisher's Note Springer Nature remains neutral with regard to jurisdictional claims in published maps and institutional affiliations. 